\title{
Narrating Animal Suffering in Ye Guangqin's Animal Stories
}

\author{
Chao Xie \\ Shanghai Normal University \& Zhejiang Gongshang University
}

Follow this and additional works at: https://docs.lib.purdue.edu/clcweb

Part of the Comparative Literature Commons

Dedicated to the dissemination of scholarly and professional information, Purdue University Press selects, develops, and distributes quality resources in several key subject areas for which its parent university is famous, including business, technology, health, veterinary medicine, and other selected disciplines in the humanities and sciences.

CLCWeb: Comparative Literature and Culture, the peer-reviewed, full-text, and open-access learned journal in the humanities and social sciences, publishes new scholarship following tenets of the discipline of comparative literature and the field of cultural studies designated as "comparative cultural studies." Publications in the journal are indexed in the Annual Bibliography of English Language and Literature (Chadwyck-Healey), the Arts and Humanities Citation Index (Thomson Reuters ISI), the Humanities Index (Wilson), Humanities International Complete (EBSCO), the International Bibliography of the Modern Language Association of America, and Scopus (Elsevier). The journal is affiliated with the Purdue University Press monograph series of Books in Comparative Cultural Studies. Contact: <clcweb@purdue.edu>

\section{Recommended Citation}

Xie, Chao. "Narrating Animal Suffering in Ye Guangqin's Animal Stories." CLCWeb: Comparative Literature and Culture 21.5 (2019): <https://doi.org/10.7771/1481-4374.3281>

This text has been double-blind peer reviewed by $2+1$ experts in the field.

The above text, published by Purdue University Press @P Purdue University, has been downloaded 44 times as of $11 /$ $07 / 19$.

This document has been made available through Purdue e-Pubs, a service of the Purdue University Libraries. Please contact epubs@purdue.edu for additional information.

This is an Open Access journal. This means that it uses a funding model that does not charge readers or their institutions for access. Readers may freely read, download, copy, distribute, print, search, or link to the full texts of articles. This journal is covered under the CC BY-NC-ND license. 


\title{
PURDUE
}

UNIVERSITY PRESS <http://www.thepress. purdue.edu>

\section{CLCWeb: Comparative Literature and Culture}

ISSN 1481-4374 <http://docs.lib.purdue.edu/clcweb> Purdue University Press @ Purdue University

CLCWeb: Comparative Literature and Culture, the peer-reviewed, full-text, and open-access learned journal in the humanities and social sciences, publishes new scholarship following tenets of the discipline of comparative literature and the field of cultural studies designated as "comparative cultural studies." In addition to the publication of articles, the journal publishes review articles of scholarly books and publishes research material in its Library Series. Publications in the journal are indexed in the Annual Bibliography of English Language and Literature (ChadwyckHealey), the Arts and Humanities Citation Index (Thomson Reuters ISI), the Humanities Index (Wilson), Humanities International Complete (EBSCO), the International Bibliography of the Modern Language Association of America, and Scopus (Elsevier). The journal is affiliated with the Purdue University Press monograph se ries of Books in Comparative Cultural Studies. Contact: <clcweb@purdue.edu>

\author{
Volume 21 Issue 5 (September 2019) Article 4 \\ Chao Xie, \\ "Narrating Animal Suffering in Ye Guangqin's Animal Stories" \\ <http://docs.lib.purdue.edu/clcweb/vol21/iss5/4> \\ Contents of CLCWeb: Comparative Literature and Culture 21.5 (2019) \\ Special Issue Suffering, Endurance, Understanding. Ed. Simon Estok, Douglas Berman, and Frank \\ Stevenson \\ <http://docs.lib.purdue.edu/clcweb/vol21/iss5/>
}

Abstract: In his article "Narrating Animal Suffering in Ye Guangqin's Animal Stories," Chao Xie analyzes animal suffering depicted in the contemporary Chinese writer Ye Guangqin's animal story collection The Tiger Dafu (2004). Through reading the interconnected suffering of animals and humans represented in Ye's works, Xie argues that Ye expresses an attitude of posthumanism which is needed to examine animal suffering. The shared victimhood between animals and humans in Ye's works, which is largely due to the process of Chinese modernization, provides a new insight into the idea of the Anthropocene. 


\section{Chao XIE}

\section{Narrating Animal Suffering in Ye Guangqin's Animal Stories}

Animal suffering is a recurrent theme in the Chinese writerYe Guangqin's anim al stories. As an acclaimed writer who has won many top-level national awards, including the Chinese Environmental Protection Literature Award, Ye has written extensively on varied forms of animal suffering caused by zoo keeping, meat eating, so on and so forth. Close readings of the animal suffering narrated in Ye's animal stories reveal the following observations: first, Ye disrupts the human-animal distinction in terms of suffering on both physical and mental levels; second, despite its significant positive aspects, the process of Chinese modernization is damaging to both animals and humans. Through reading the animal suffering narrated in Ye's animal stories collected in The Tiger Dafu (2004), this article argues that Ye conveys a clear posthumanist attitude which can contribute to the analysis of animal suffering, and the shared victim hood of animals and humans caused by modernization provides a new insight into the idea of the Anthropocene.

Suffering has long been a contested field. As "a subjectively experienced state" (Aaltola 49), suffering defies any objective language and understanding. In her sem inal work The Body in Pain (1985), Elaine Scarry recognizes that pain cannot be denied, but it also cannot be confirmed by others because pain is "originally an interior and unsharable experience" (16). Scarry further argues that, it is the "unsharability" of pain that leads to its resistance to language. Scarry's argument is echoed by A. W. Frank and Iain Wilkinson who both maintain that suffering is "unspeakable" because it is opposed to reality and reason $(345 ; 10)$. These critics imply that, as long as there is a divide between subject and object, suffering will continue to defy any form of definition. Nevertheless, as Elisa Aaltola notices, the human inability to define suffering may risk justifying violence towards others and causing confusions in human thinking (50). Thus said, defining suffering is actually caught in a dilemma: on o ne hand, defining the term seems impossible; on the other hand, leaving the term unscrutinized will eventually perpetuate violence. Compared with human suffering, animal suffering is a more complicated issue. If we cannot even truly understand the suffering of a hum an being, how can we know the pain of a different species? If we follow Aaltola's thinking, then, to leave animal suffering unanalyzed will undoubtedly lead to an excuse for not caring. The problem here is the following: how can we assess animal suffering? And, will the impossibility of defining animal suffering cancel out the very existence of animal suffering?

In modern Western culture, animals' abilities to feel pain are the starting point of extending ethical consideration from humans to animals. René Descartes considered animals as machines which had no mind and were incapable of feeling pain. This idea of treating animals as mere automata was later rebuked by philosophers such as Jean-Jacques Rousseau, who viewed animals as equal sentient beings as humanity. Jeremy Bentham, the founder of utilitarianism, drew humans' attention to animals' capability of suffering and asked in his influential Introduction to the Principles of Morals and Legislation (1780): "the question is not, Can they reason? Nor can they talk? but, Can they suffer" (236)? Following Bentham, the utilitarian Peter Singer relates suffering and happiness to morality. Because to suffer is morally undesirable, humans should therefore prevent themselves from causing pain, regardless of the species of the sufferer. Despite the fact that Rousseau, Bentham, and Singer's views towards animal suffering are anthropocentric, as they all use hum ans as a yardstick to judge anim als, these philosophers actually provide a useful way of examining animal suffering, that is, animal suffering can be learned through the mediated experience of humans. My concern here is that the perspective of posthum anism is needed to study animal suffering. My proposal is based on two reasons: first, as we are now in the Anthropocene, "a new geological epoch or era" in which human activities have dramatically changed the "Earth system" (Steffen et al. 842), animal suffering, in most cases, is actually caused by humans. The idea of posthumanism gives us a chance to reevaluate our dom inant stance towards animals; second, as em pirical evidence and philosophical studies suggest, the human-animal distinction is only of degree but not of kind, it is therefore impossible to analyze animal suffering separately from that of human beings. This posthumanist perspective materializes pain into what Javier Moscoso called "an intersubjective reality" that can be analyzed (7). Ye's animal stories, which foreground the animal suffering through blurring the boundary between humans and animals, provide a chance to look at animal suffering from a posthumanist perspective.

Notwithstanding that critics cannot reach a consensus on the definition of posthumanism, the core of the term refers to the challenge of the deep-rooted idea of anthropocentrism which puts human beings in the center of the natural world. Drawing on the developments in both the humanities and empirical sciences, Donna Haraway announces in her seminal essay "A Cyborg Manifesto" that "the boundary between human and animal is thoroughly breached. The last beachheads of uniqueness have 
been polluted" (151). Cary Wolfe echoes Haraway's thesis by arguing that posthumanism "engag[es] directly the problem of anthropocentrism and speciesism," and "the animal problem" is actually "part of the larger question of posthumanism" (What is xix; xxii). The two critics have pointed out the power of posthumanism, in which the porous human-animal distinction is an integral part of deconstructing the anthropocentrism. Close readings of Ye's animal stories illustrate that, the writer shows an attitude of posthumanism through which we can look at animal suffering in a new light.

As both Shudong Wang and Kelong Tang notice, almost every animal story composed by Ye ends with a tragic note $(448 ; 218)$. Although the two critics are correct in pointing out that most of Ye's animal stories involve suffering, be it of humans or of animals, they have actually overlooked one phenomenon which many of Ye's animal stories share - that is, the suffering of animals is invariably interlinked with that of humans. Many of Ye's animal stories foreground the interconnected suffering of animals and humans. The story "The Bear Shujuan" is a typical case in point. The animal protagonist Shujuan suffers serious malnutrition and anemia in a zoo due to the lack of food. To make things worse, when he realizes that the old and sick bear can no longer bring economic benefits, the zoo director sells Shujuan to a private circus in which the animal is badly mistreated and forced to perform in public to entertain spectators. In the story, Ye denounces the modern zoo system which has altered the natural habits of animals and viewed animals as mere tools for making money. But we should also note that the bear's suffering is closely connected with the suffering of her breeder Lin Yao. After taking care of the bear for many years, Lin develops a strong affection for the bear. The worsening health condition of the animal torments Lin to a great extent. Shocked by the fact that Shujuan is sold to the circus, Lin feels obliged to find the animal. In his journey to search for Shujuan, the breeder suffers great physical and mental pain, because he is considered a lunatic due to the deep sympathy he shows to the animal in public. The reason why the breeder suffers is that he does not consider the animal an instrument for making money as most people do, but "a friend" (Ye 203; unless indicated otherwise, all translations are mine) who can understand and respond to human feelings. Sadly, Lin's egalitarian view on the human-animal relationship is not accepted but ridiculed by other people. The connection between the suffering of the animal and that of the breeder is dramatized in the end of the story: the desperate bear accidently beats Lin to death, and the paw of the animal is sent to a restaurant as food. Apparently, Ye connects the suffering and deaths of both the bear and the human character to demonstrate the interrelated fate between humans and animals on both physical and spiritual levels.

Drawing on the French philosopher Sim one Weil's idea that vulnerability is a mark of existence, Anat Pick calls our attention to the common risk of injury and the inevitability of death shared by both humans and nonhuman animals. The relationship between vulnerability, existence, and beauty, as Pick further argues, applies across the species barrier and delivers us beyond the domain of the human (3). Pick's statement is clearly posthumanist, as she has used "the flesh and blood vulnerability" as a basic experience to transcend the human-animal distinction. Pick's thought provides a useful lens to analyze the shared suffering between humans and animals depicted in Ye's animal stories. True as it is, in the case of "The Bear Shujuan," physical pain resulting from injuries and vulnerabilities, as Pick indicates, helps us transcend the human domain. But one would need to add that, spiritual suffering shared by both Lin and the bear also contributes to the breakdown of the species barrier. What is more, the suffering of the breeder and the animal is intertwined in the story, which further destabilizes the humananimal distinction.

Similarly, the story "The Monkey Village Head" represents the interconnected animal and human suffering through criticizing zoo-keeping practices and blurring the human-animal boundary. Ye insists in the story that trapping animals in the wild and confining them in cages are cruel deeds which cause great torments to animals. During the process of trapping golden monkeys, the local villagers cruelly beat the animals with cudgels, resulting in fractures. Ye juxtaposes in the story the suffering of monkeys on both physical and mental levels with their dignity which is traditionally considered as a hum an quality. Suffering great pain while being confined in cages, the monkeys refuse to accept the food provided by humans, and many of them deliberately starve to death. Here, the monkeys display subjectivity, to be more specific, a strong will of not to be conquered. This subjectivity greatly challenges the humananimal boundary, because it is traditionally believed to be a human property. However, the monkeys are not the only creatures that suffer great pain. The story features a human protagonist Hou Zicheng who is strongly against capturing the animals. While attempting to scare away the monkeys in order to prevent them from being captured, Hou is severely beaten by other villagers. The empathy Hou shows towards the monkeys deserves our special attention here. When the captive old monkey and Hou look at each other, "they both feel as if they were struck by a lightning" (130). This emotional resonance resulting from the interspecies gazing actually implies that the animal and the human can communicate and exchange feelings. Hou does not view the monkeys as property which can be disposed of at will; 
instead, he shows great empathy towards the monkeys, as if he could feel the pain the monkeys suffer. The philosopher Emmanuel Levinas has argued that em pathy and identity with the Other are potential cornerstones of a radical interspecies ethics and politics (Weisberg 98). This idea is echoed by the posthumanist Jodey Castricano who proposes that an ethics based on empathy can be of crucial importance in decentering human exceptionalism (5). Both of the critics stress the ethical dimension involved in empathy, which is crucial to breach the human-animal distinction. Going back to the story "The Monkey Village Head," the empathy towards the monkeys Hou displays, which arises from shared physical and mental pain, not only implies ethical obligations humans should assume to animals, but also calls anthropocentrism into question.

The two stories analyzed above both accentuate the interlinked animal and human suffering by endowing animals with human qualities. But in the story "The Snake Erchan," the interconnected suffering is emphasized as the human protagonist is endowed with animal characteristics. The story features a character called Erchan who is believed by many villagers to be the offspring of a female snake. Not only does Erchan have the appearance and habits of a snake, but he also shares the sentiments of the animal. Whenever he sees Lao She - a cook who makes a fortune out of selling and cooking snakes - catching snakes or transporting the animals to restaurants in cities, Erchan is deeply tormented by anger and pain. Identifying with the suffering of the animal, Erchan se cretly sets free the snakes Lao catches in the village. The most outrageous thing is that, when a big old snake (whose name is also Erchan), which is assumed to have lived for thousands of years, is killed and cooked by Lao, Erchan suddenly drops dead. In this case, the human-animal distinction is not disrupted by raising the animal to the level of human, but through the deterioration of hum an state to that of the animal. Erchan in the story is a hybrid creature, a "humanimal" form that predicated on the refusal of the hum an/animal binary (Wolfe, Animal Rites xiii). In connecting snakes and Erchan in terms of name, appearance, habits, suffering, and death, Ye profoundly destabilizes the human-animal border. The animal suffering and the human suffering, as the story indicates, is not only interconnected, but actually merges into one.

The disruption of hum an-animal distinction in terms of suffering in Ye's animal stories reveals at least two things: first, as pain afflicted on animals causes pain to humans, we should therefore avoid causing animal suffering both for the sake of animals and for ourselves. Second, the tearing down of the hum ananimal boundary opens humans to hybrid modes of existence and pushes us to reevaluate our dom inant stance with relation to animals. Moreover, this interconnected suffering also indicates that the suffering of animal ought not to be examined isolated from that of humans. This observation introduces an important question: are there any institutional or ideological causes for the shared victimhood of suffering?

In his Animal Rites: American Culture, the Discourse of Species, and Posthumanist Theory (2003), Wolfe highlights out "the humanistic discourse of species" that connects the exploitation of animals to that of marginalized peoples: "...as long as this humanist and speciesist structure of subjectivization remains intact, and as long as it is institutionally taken for granted that it is all right to systematically exploit and kill nonhuman animals simply because of their species, then the humanist discourse of species will always be available for use by some humans against other humans as well, to countenance violence against the social other of whatever species - or gender, or race, or class, or sexual difference" (8, Italics in original). As Wolfe here indicates clearly, "the humanist discourse of species" legitimizes the oppressions on unprivileged peoples through holding fast to speciesism. In Ye's animal stories, "the humanist discourse of species," in most cases, takes the form of the influence of modernization, which is both damaging to animals and destructive to humans.

Although scholars have come up with different possibilities for the starting date of the Anthropocene (Ruddiman 261; Zalasiewicz et al. 196), it is commonly accepted that modernization facilitated if not directly led to the Anthropocene. In the West, modernization is initiated by the Industrial Revolution which began in England in the eighteenth century. According to Will Steffen and other scholars, the Anthropocene began with the advent of the Industrial Revolution which is around 1800 (842). According to these scholars, the effects of the Anthropocene became more pronounced during "the great acceleration" following the Second World War, a period that witnessed unprecedented environmental problems, such as air pollution, climate change, and animal extinctions. Despite the fact that modernization emerged in China in the mid-nineteenth century when the country opened its doors to the West, it is generally believed that modernization did not truly unfold until the 1980 s, when a variety of policies relating to politics, economics, and social reforms began to take effect (Chen 109). Chinese modernization can actually be situated in the context of the Anthropocene, as environmental problems caused by the process of modernization have not been less serious than for its western counterpart.

Despite being a deeply contested term, the Anthropocene is commonly understo od as a geological epoch that is characterized by grand environmental issues, such as climate change, disruptions in 
element cycles, and the rapid depletion of biodiversity (Steffen 843). More often than not, the term is used in an abstract way. Morten Tønnessen and Kristin Oma forcefully point out that, the discussions of the Anthropocene have been dominated by large-scale phenomena, whereas the role and place of animals has received little attention (ix). Tønnessen and Oma's observation provides a clue for reading Ye's works in terms of the Anthropocene. In her animal stories, Ye foregrounds the money-oriented mindset, the loss of traditional culture, and the craving for novel food, each associated with Chinese modernization, to represent in concrete ways how animals are objectified and exploited in a humandom inated world. More importantly, her animal stories reveal how animal suffering caused by humans can be equally damaging to humans themselves.

The story "The Bear Shujuan" sets its background against the economic transition period when stateowned enterprises, such as zoos, had to adjust their economic structures in order to sustain their operations. During the 1990s, China witnessed a period in which planned economy gradually gave way to market economy. Undoubtedly, this economic transition, which is considered as an important step of Chinese modernization, has boosted the national economy to a great extent. But it has also given rise to a variety of environmental problems including damages to the habitats of wild animals and the deterioration of the living conditions of captive animals. The second episode of the story begins with the sentence: "Everyone is worried about money" (180). This voracious desire for money underlies the interconnected suffering of the bear and the breeder. Under the money-oriented mindset, the bear is badly mistreated for the end of men. Similarly, Lin finds himself a misfit, which brings him unbearable pain. After realizing the fact that Lin despises the idea of using animals as a tool to attract foreign investment, Lin's colleagues sharply criticize him for being unrealistic. One colleague points out that "the economic society is a world where you should put your face into your crotch" (186). The other maintains that adopting animals in zoos and using them to advertise for sponsors have become a national trend, so the idea should be accepted as it is. As the colleagues' remarks imply, animals are implicated in the overwhelming modernization process, so one cannot consider animal issues without referring to money, and those who cannot keep up with the trend will not be accepted by society. It is this money-oriented mindset, which is prevalent in the process of the Chinese modernization, that breaks the species boundary as it reduces both the bear and the breeder to Others. In "The Monkey Village Head," the local villagers view the monkeys they capture as "living money" and insist that those who prevent them from selling the animals to zoos be punished (127). Moreover, the villagers keep arguing about the payment of capturing monkeys and the compensation they should get from the injuries due to the capturing. In this regard, Ye does not only reveal the cruelties of animal captivity, but also criticizes the profit chain related to the modern zoo system.

Randy Malamud maintains that the physical, financial, and cultural dimensions of the acquisition of captive animals and the proliferation of zoos as institutions actually reflect the "magnitude" which Stephen Greenblatt views as a crucial part of modern capitalist culture (11). In China's case, it is the modernization which gives priority to money that leads to the flourishing of zoo practice that causes great animal suffering. Going back to Ye's animal stories, we need to add that, through criticizing the practice of zoo keeping which causes great animal suffering, Ye reveals that the power of modernization can be equally damaging to humans.

Ye also reveals the detrimental influences of modernization to both animals and humans by drawing attention to the loss of traditional culture. In the story "The Snake Erchan," Lao despises the local villagers who show respect and gratitude to the animal. In Lao's eyes, the local villagers are backward, uncivilized, and superstitious.

When commenting on the villagers' unwillingness to eat snakes, Lao says thus: "The villagers are too stubborn. The wind of the Reform and Open-up has not yet blown into this village" (162). Hum orous as the statement may sound, Lao has distinguished himself from the local villagers as a modern man. Lao disbelieves the local legend which considers snakes as ancestors and says: "Legends are always legends. If we believe in them, we can neverearn money" (169). As legends cannot bring benefits, they should therefore not be taken in an earnest way. This comment illustrates a utilitarian attitude, which views animals only in terms of profit. Lao's disavowal of traditional culture and his insistence to maintain his superiority over animals explain why he disregards the suffering of both animals and humans. With this in mind, the pain afflicted on snakes and Erchan actually implies the precarious situation of traditional culture under the attack of modernization.

China enjoys a long tradition of respecting animal lives and viewing animals and humans as an inseparable whole in terms of religion, folk beliefs, and value systems. Taoism views humans and nonhuman animals as equal beings which belong to Great Nature (Tao 道) that changes constantly. This idea finds its eloquent expression in Zhuang Zi's statement: "Heaven, Earth, and I were produced together, and all things and I are one" (Zhuang "Zhuangzi"). Seen from the perspective of Taoism, the 
harmonious relationship between humans and animals conforms with Tao, whereas the mistreatment and random killing of animals are against Tao. Chinese folklores are also abundant in examples that view humans and animals as inseparable. For instance, the well-known folktale The Legend of White Snake features a snake transforming into a beautiful woman to return the favor to a man who once saves her life. ${ }^{1}$ If we accept the idea that Chinese culture and philosophy have the tradition to be kind to nonhuman animals, how can we justify the large amount of animal suffering appeared in Ye's animal stories, especially when we take into account the fact that animal suffering is a common theme many contemporary Chinese writers tackle with in their works? There is no denying that humans'brutalization towards animals has existed since time immemorial. But in China's case, it is the process of modernization that greatly intensifies the human-animal relationship. Mang Ping notices that the humananimal relationship in China has witnessed an abrupt change in the latter half of the twentieth century, as the traditional respectful view towards animals was replaced by a narrow anthropocentric view. Mang further argues that the year 1978, which saw the implement of Reform and Open-up policy, is the point when the tension between humans and animals started to reach an unprecedented level (273). Echoing Mang's idea, Wang Zhihe regards the nihilistic stance towards traditions as an important cause to "the predicament of Chinese modernization" (Wang 53). Wang argues that, due to the process of Chinese enlightenment, or rather, the Chinese modernization, Chinese people are eager to break away from their traditional cultures which they think are the stumbling block to progress. Yet, the indiscriminate split from the traditional cultures also means that they have given up the respect for nature which many Chinese traditions advocate. Both Mang's and Wang's arguments provide useful social and ideological contexts which are crucial to understand Ye's animal stories. As "The Snake Erchan" indicates, the traditional holistic view towards the human-animal relationship is dramatically threatened as the idea of modernization takes hold of the country.

In many of Ye's animal stories, the interconnected animal and human suffering resulting from modernization also manifests itself through the craving for eating novelties. "The Bear Shujuan" features a hypocritical restaurant which advocates for novel food that can bring "the pleasure of taste buds" and "the nourishment of spirit" (194). According to the restaurant, the more exotic and unfamiliar the food material is, the higher the status of the eater is. This craving for novelties has turned animals into a semiotics of social status. Seen in this regard, animals in the story have become what Carol Adams called "the absent referent" (13), an oxymoronic situation in which animals are both present and absent. In the story, Ye has drawn our attention to animal suffering which has been downplayed by humans' pursuit of culinary delight as well as vanity. The author goes into great detail to depict varied forms of animal killings, including skinning snakes alive, so on and so forth.

Yue Gang once argued that Chinese modernization had brought with it "the sudden return of insatiable voracity" (Yue 2). After experiencing a considerable period of incessant wars and natural disasters, Chinese people, especially the middle class, start to enjoy material abundance and rehabilitate their buds thanks to the process of modernization. Yue's thesis is echoed by Judith Farquhar, who pointed out that, in the 1990s, Chinese "indulgence of appetite is a highly visible, even flamboyant, aspect of a growing consumer regime" (3). As the two critics suggest, the blind pursuit for money and power has given birth to consumerism which liberates the taste buds of Chinese people and subsequently brings great suffering to animals. Under the influence of the frenetic desire for novel food, animals have become properties that can be disposed at will, and the killing and ingestion of animals have been legitimized as what Jacques Derrida once called "a noncrim inal putting to death" (112). Going back to Ye's animal stories, one can note that the craving for novel food brings suffering to both humans and animals. In "The Bear Shujuan," the desire for novel food is an important reason that leads to the suffering and deaths of both the bear and Lin.

Through narrating the interconnected suffering of animals and humans caused by Chinese modernization which takes the form of the money-oriented mindset, the loss of traditional culture, and the craving for novel food, Ye has illustrated the specific and concrete ways the Anthropocene can be thought of in terms of animals. As Ye's animal stories show, both animals and humans have fallen prey to the process of the rapid economic growth. Under the powerful influence of modernization, animals suffer great pain as they are reduced to instruments to make money or to an element in the semiotics of human status. Meanwhile, humans are also tortured as their empathy-based judgement and conscience have been distorted by the money-oriented utilitarianism. Bruno Latour argues that, "the

${ }^{1}$ As one of the famous Chinese folktales, The Legend of White Snake has mainly been passed down through generations orally. The earliest written version of the legend can be traced back to Taiping Guangji compiled in Song Dynasty (AD 960-1279). Despite the plot of the legend varies as time goes on, the metamorphosis of a snake into a woman remains unchanged. 
point of living in the epoch of the Anthropocene is that all agents share the same shape-changing destiny, a destiny that cannot be followed, documented, told, and represented by using any of the older traits associated with subjectivity or objectivity" (15). With this comment, the French philosopher is suggesting that, humans and non-human nature, including animals, are not in binary opposition, but are intermeshed in the same fate under the current Anthropocene era which is witnessing the unprecedented influence of hum anity. Through disrupting the border between anim als and hum ans, and that between subjectivity and objectivity, Ye has created a new way to assess animal suffering, that is, to analyze animal suffering in parallel to that of humans. Moreover, the writer has brought to the forefront "the spiritual dilemma and the predicament of life that humans and animals are confronting together" under a human-dominated world (Ye 5).

We should also note that Ye's animal stories have strong realistic elements, as most of them are based on the writer's experience in Qinling Mountains (in northwest China) where she served as the vice-secretary for several years and heard related stories from the local villagers. What is $m$ ore, as an animal activist who enthusiastically engages in animal and environmental protection, ${ }^{2}$ Ye consciously blends thinking about animal rights in her writings, calling for readers to show their concerns for animal suffering that has mainly been caused by human activities. In her documentary work The Old Town (2004), another book which grew out of her working experience in Qinling, Ye sharply criticized hum ans' mistreatment of animals and showed strong empathy for animals' feelings. In fact, it is essential to place Ye's animal stories in relation to the background of the emergence of the Chinese animal fictions, which arise directly out of environmental issues related to the process of modernization. According to Wang Shudong, from 1990s onwards, especially after the implement of the market economy in China, the critique of the modern Chinese culture, which is characterized by anthropocentrism, consumenism, and technology, reached its climax in contemporary Chinese literature (Wang S. 169). As the ecological awareness began to garner wide attention among Chinese writers and literary critics in the 1990 s due to worsening environmental problems in China, animal fictions have become an important genre in contemporary Chinese literature. Writers including Ye, Guo Xuebo, and Zhangwei focus on realistic animal issues in China through representing in their works the miserable conditions of animals and the radical conflicts between humans and animals resulting from the ideology of modernization. Judging from these facts, it is safe to say that the interconnected suffering of animals and humans depicted in Ye's animal stories carry realistic relevance, and should be read as a warning against the detrimental force of modernization.

Actually, the interconnected suffering between humans and animals is very real outside of Ye's stories. The passion for novel food represented in Ye's stories can find its realistic equivalent in China. For instance, the ever-increasing demand for shark fin among Chinese middle-class customers in recent years has driven sharks all over the world to the border of extinction. According to the reportage of China Youth Daily, China now has around 100 million shark fin customers. This high demand for shark fin has led to increasingly serious shark poaching globally. Nowadays, $95 \%$ of the global shark fin trade involves China (Liu). This Chinese craze for shark fin has brought the animal great pain as some sharks are finned alive on board and then thrown back into the sea dying a prolonged death. Just like those who have irresistible appetite for novel food depicted in "The Bear Shujuan," people consume shark fin as much for its novelty as a food to satisfy their ravenous palates as they do for semiotic reasons of their social status. The overfishing of sharks now proves to be damaging to humans in terms of aquaculture industry, as the marine ecology is profoundly disrupted. Therefore, we cannot read Ye's animal stories literarily as stories, they actually have to do with the ongoing plight of both animals and humans in contemporary China.

It is through the perspective of posthumanism that I try to make sense of the animal suffering narrated in Ye's animal stories. Ye not only draws our attention to the porous boundary between animals and humans in terms of suffering, but also implies that animals and humans are intermeshed in the same fate under the era of the Anthropocene. Instead of representing the Anthropocene in an abstract and intangible way, Ye provides a new insight into the Anthropocene by prompting us to consider what the Anthropocene era really means in terms of the human-animal relationship. Written in a realistic style, Ye's animal stories also remind us that engaging with questions about animals and the Anthropocene actually means engaging with very real problems we face in the twenty-first century. One important message Ye intends to convey in her animal stories is that, animals do deserve our respect

${ }^{2}$ While working inside Qinling Mountains, Ye was committed to promoting ecological ideas and raising local villagers' awareness of environmental protection. As a representative of the National People's Congress, Ye has helped to establish Jingwei Wetland Reserve in Xi'an. 
not only because they are not ontologically different from us, but because they cannot be separated from us, especially when it comes to the issue of suffering.

\section{Works Cited}

Aaltola, Elisa. Animal Suffering: Philosophy and Culture. Palgrave Macmillan, 2012.

Adams, Carol. The Sexual Politics of Meat: A Feminist-Vegetarian Critical Theory. Continnum, 2010.

Bentham, Jeremy. Introduction to the Principles of Moral and Legislations. London: B. Bensley, 1780.

Castricano, Jodey. Animal Subjects: An Ethical Reader in a Posthuman World. Wilfrid Laurier UP, 2008.

Chen, Hong. "The Plight of Dogs in the Country-City Gap: Reading Chinese Dog Narratives across Genres. " Concentric: Literary and Cultural Studies, vol. 43, no. 1, 2017, pp. 97-117.

Derrida, Jacques. "'Eating Well,' or the Calculation of the Subject: An Interview with Jacques Derrida." Who Comes After the Subject? edited by Eduardo Cadava, Peter Connor, and Jean-Luc Nancy, Routledge, 1991, pp. 96-119.

Farquhar, Judith. Appetites: Food and Sex in Post-Socialist China. Duke UP, 2002.

Frank, A. W. "Can We Research Suffering?" Qualitative Health Research, vol. 11, no. 3, 2001, pp. 353-62.

Haraway, Donna. "A Cyborg Manifesto: Science, Technology and Socialist Feminism in the Late Twentieth Century." Simians, Cyborgs, and Women: The Reinvention of Nature, Routledge, 1991, pp. 149-82.

Latour, Bruno. "Agency at the Time of the Anthropocene." New Literary History, vol. 45, no. 1, 2014, pp. 1-18.

Li, Fang, et al. Taiping guangji (Notes on peace). Zhonghua shuju, 2003.

Liu, Kun. "Guojizuzhi laihua huyu: dui shayu zuijialiuqing" ("The call from the international organization: show mercy to sharks"). China Youth Daily, www.zqb.cyol.com/node/2007-07/23/zgqnb.htm. Accessed 23 July 2017.

Malamud, Randy. Reading Zoos: Representations of Animal and Capacity. Macmillan, 1998.

Mang, Ping, et al. Wuwoxiangrong de shijie: zhongguoren de Xinyang shenghuo yu dongwuguan (The world of the interrelated self and other: Chinese beliefs, lives and views of animals). Zhongguo zhengfadaxue chubanshe, 2009.

Moscoso, Javier. Pain: A Cultural History. Palgrave Macmillan, 2012.

Pick, Anat. Creaturely Poetics: Animality and Vulnerability in Literature and Film. Columbia UP, 2011.

Ruddiman, William, "The Anthropogenic Greenhouse Era Began Thousands of Years Ago." Climatic Change, vol. 61, no. 3, 2003, pp. 261-93.

Scarry, Elaine. The Body in Pain: The Making and Unmaking of the World. Oxford UP, 1985.

Steffen, Will, Jacques Grinevald, Paul Crutzen and John McNeill. "The Anthropocene: Conceptual and Historical Perspectives." Philosophical Transactions of the Royal Society, no. 369, 2011, pp. 842-67.

Tang, Kelong. Zhongguoxiandangdaiwenxue dongwuxvshiyanjiu (The research of animal narratives in contemporary Chinese literature). Nankaidaxue chubanshe, 2010.

Tønnessen, Morten, et al. Thinking about Animals in the Age of the Anthropocene. Lexington Books, 2016.

Wang, Shudong. Shengtaiyishi yu zhongguo dangdaiwenxue (The ecological awareness and contemporary Chinese literature). Zhongguo shehuikexue chubanshe, 2008.

Wang, Zhihe. "Zhongguo de houxiandaihua yu dierci qimeng" ("The Chinese postmodernization and the second enlightenment"). Makesizhuyi yu xianshi, vol. 2, no. 8, 2007, pp. 51-60.

Weisberg, Zipporah, "The Trouble with Posthumanism: Bacteria Are People Too." Critical Animal Studies: Thinking the Unthinkable, edited by John Sorenson, Canadian Scholars'P, 2014, pp. 93-116.

Wilkinson, Iain. Suffering: A Sociological Introduction. Polity P, 2005.

Wolfe, Cary. Animal Rites: American Culture, the Discourse of Species, and Posthumanist Theory. The U of Chicago $\mathrm{P}, 2003$.

Wolfe, Cary. What is Posthumanism? U of Minnesota P, 2010.

Ye, Guangqin. Laohu dafu (The tiger dafu). Taibai wenyi chubanshe, 2004

Ye, Guangqin. Lao xiancheng (The old town). Zhongguo gongren chubanshe, 2004.

Yue, Gang. The Mouth That Begs: Hunger, Cannibalism, and the Politics of Eating in Modern China. Duke UP, 1999.

Zalasiewicz, Jan, et al. "When did the Anthropocene begin? A Mid-twentieth Century Boundary Level is Stratigraphically Optimal." Quaternary International, vol. 383, 2015, pp. 196-203.

Zhuang, Zi, "Zhuangzi qiwulun" (The adjustment of controversies). Translated by James Legge. www.ctext.org/zhuangzi/adjustment-of-controversies. Accessed 1 August 2017.

Author Profile: Chao Xie is a member of "Innovative Team of High-level Program in Comparative Literature and World Literature at Shanghai Normal University." He teaches English language and British literature in the School of Foreign Languages at Zhejiang Gongshang University. His interests in research include ecocriticism and British poetry. Xie's articles appeared on Journal of Poyang Lake, Urban Cultural Studies, and Kritika Kultura. Xie is currently working on a project on climate writings in contemporary British poetry. Email: <chaoxie1987@126.com> 